\title{
Thyroid Hemiagenesis in a Young Boy: A Rare Case Report
}

ROHINI R PATTANSHETTI, IRANNA M HITTALAMANI, NAMIT M GARG, SHIVU JAYADEV

\section{ABSTRACT}

Thyroid hemiagenesis is a rarely encountered developmental anomaly with only around 330 cases reported so far. Left lobe hemiagenesis is more common than the right lobe, with female preponderance.

We report a case of hemithyroid agenesis in a young boy who presented with a painless neck swelling. Left lobe of thyroid was not visualised on USG, along with few tiny cystic nodules in right lobe and normal isthmus. Findings were confirmed on CT and showed a sub-clinical hypothyroid state on thyroid profile. The mechanism behind hemiagenesis is poorly understood. USG is reliable investigative tools to appropriately detect thyroid hemiagenesis and the thyroid pathologies associated with it.

Keywords: Computed tomography, Hypothyroidism, Thyroid gland, Ultrasonography

\section{CASE REPORT}

A 10-year-old boy presented with a painless neck swelling [Table/Fig-1] with no clinical signs of hyper/hypothyroidism. On examination, a small, firm swelling was present on the right side of the anterior part of neck overlying the thyroid cartilage which moved with deglutition. The patient was referred to our department for USG with clinical suspicion of goitre. Keeping in mind the differential diagnoses for a solitary thyroid nodule viz., thyroid hemiagenesis, benign nodules like follicular adenoma and colloid cyst or malignant thyroid nodules like papillary carcinoma of thyroid etc., thyroid USG was performed. Ultrasonographically, right thyroid lobe measuring $1.0 \times 1.3 \times 2.5 \mathrm{~cm}$ with regular margins was seen between right carotid artery and trachea, behind the sternohyoid and sternothyroid muscles. The thyroid isthmus was also seen adjacent to the right lobe, wrapped around the cricoid cartilage [Table/Fig-2]. Few tiny well circumscribed, round,wider than tall, cystic nodules were noted in the right lobe of thyroid with unremarkable vascularity. These findings were suggestive of benign thyroid nodules and were reported as American College of Radiology-Thyroid Image Reporting and Data System (ACR-TIRADS) TR1 category [1]. The left lobe was not visualised which precipitated us to further evaluate for hemiagenesis of thyroid by CT-scan. Non enhanced CT study of the neck was performed with sections taken from the base of skull to the superior mediastinum, $27 \times 9.4 \times 29 \mathrm{~mm}$ sized hyperdense thyroid tissue including only the right lobe and isthmus were seen with a few tiny hypodense nodules of which the largest nodule measured $4.6 \times 5.1 \times 7 \mathrm{~mm}$. No ectopic thyroid tissue was seen in these sections [Table/Fig-3].
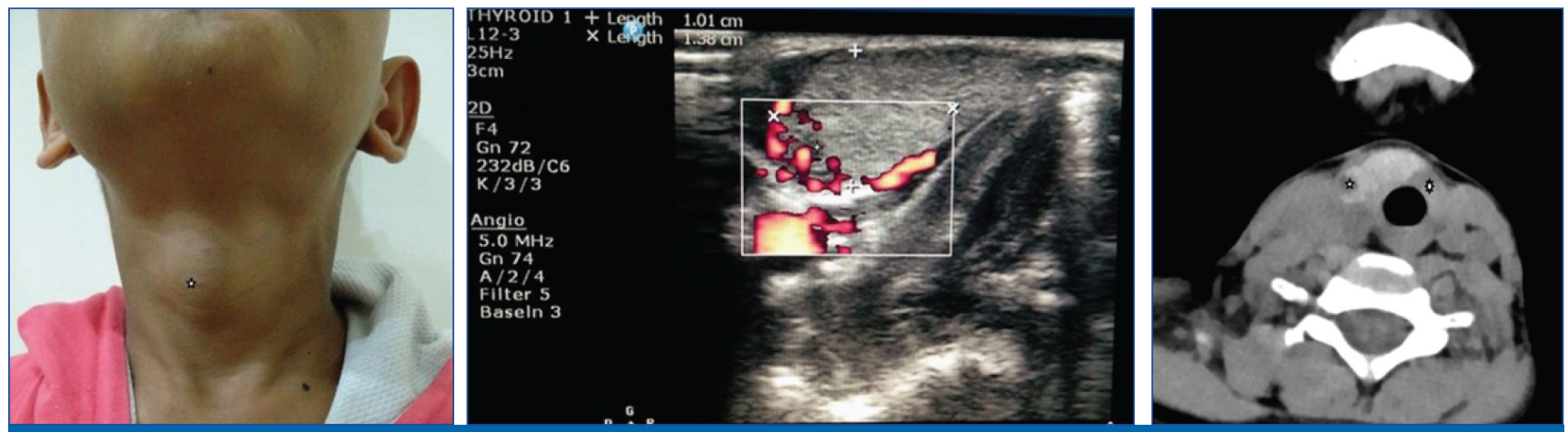

[Table/Fig-1]: Clinical image showing swelling $\left(^{*}\right)$ on the right side of neck. [Table/Fig-2]: USG showing Right lobe of thyroid (denoted by measurements) with a small hypoechoic nodule and visualised isthmus. [Table/Fig-3]: A well defined hypodense nodule $\left(^{*}\right)$ in the right lobe of thyroid. Right lobe and isthmus are visualised and not the left lobe $\left(^{*}\right)$. 


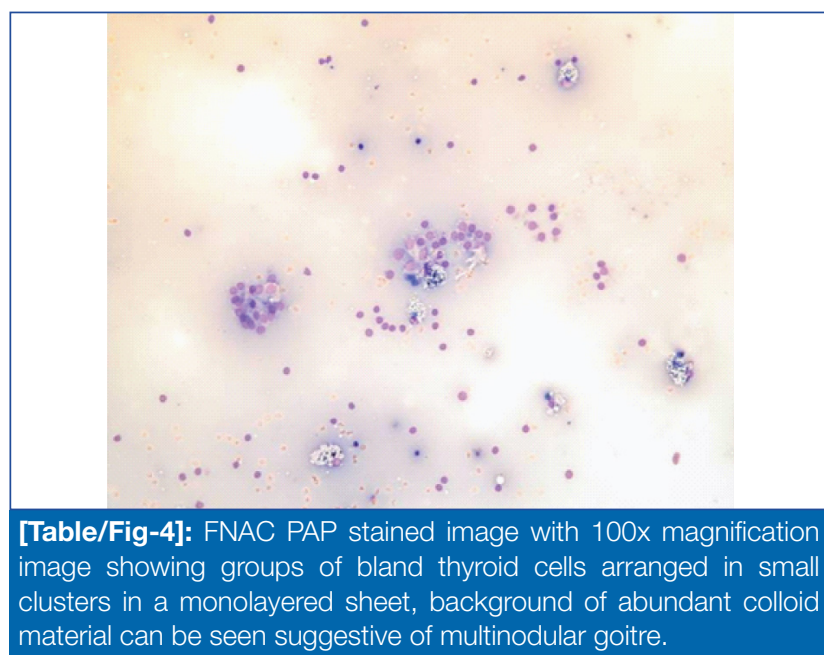

The thyroid profile test revealed TSH was exponentially raised (20.275 $\mathrm{\mu l} \mathrm{U} / \mathrm{mL})$. However, the free T4 levels were within normal limits $(6.9 \mu \mathrm{g} / \mathrm{dL})$ signifying a subclinical hypothyroid status. FNAC was also conducted as per the clinician's request which suggested the diagnosis of nodular goitre [Table/Fig-4]. The patient was advised thyroid supplements in the form of $50 \mu \mathrm{g}$ of L-thyroxine per day for a month and was asked to visit a month later for follow up. However, the patient defaulted and was lost for follow-up.

\section{DISCUSSION}

Thyroid hemiagenesis has been reported to be a rare entity with an approximate of 330 cases reported so far [2]. According to the recent data published by ORPHANET the worldwide prevalence is 25 per 100,000 . Although, owing to its incidental presentation, its true incidence is not estimated [3].

The thyroid gland is the first organ to start developing as early as 24 days after fertilization. The thyroid gland starts developing as a median endodermal thickening between the first and second pharyngeal pouches between the tuberculum impar and copula. It is then seen as a small outpouching called as the thyroid primordium. The thickened endoderm further invaginates to form a furrow caudal to the median tongue bud in fourth week of gestation. The gland then descends caudally in front of the hyoid bone and the developing laryngeal cartilages. The path traversed by the thyroid gland is a temporary tract which connects it to the tongue at the foramen caecum, which further disappears by the end of seven weeks. The hollow thyroid primordium is further converted to a solid organ by differentiation of the lining cells into the follicular, parafollicular cells and the connective tissue. It divides into the left and right lobes to be connected by the isthmus. The differentiation of cells is complete by the end of seven weeks to full size and the final location in the neck. However, it reaches a fully functional adult state by the end of 35 weeks $[4,5]$.
The mechanism underlying the thyroid hemiagenesis in humans is poorly understood and has been unexplained so far. Although, a strong genetic association has been speculated along with abnormal descent of the developing thyroid lobes [6]. It has been reported in mice to be associated with complex heterozygous FOXE1/NKX2-1(14q13) and PAX 8 (2q12-q14) gene mutations [7]. These are the genes involved in the thyroid follicular cell development and expression of thyroid specific genes, and hence believed to be involved in the thyroid dysgenesis.

The most common hormonal disorder occurring in a case of hemiagenesis is hyperthyroidism. Hypothyroidism, Hashimoto's thyroiditis, multinodular goitre, euthyroid adenoma and papillary carcinoma are also known to occur in cases of thyroid hemiagenesis [8]. In the present case, there was evidence of subclinical hypothyroidism with normal T3 and T4 levels.

Either of the lobes can fail to develop and isthmus may be present or even absent. The left lobe hemiagenesis is seen four times more than the right lobe hemiagenesis. Although, thyroid hemiagenesis is found three times more often in women than in men but the present case was a young boy with left lobe agenesis [9]. FNAC remains a gold standard to confirm the disease in the existent thyroid lobe to avoid unnecessary surgical procedures.

Radionuclide scintigraphy studies would be best to detect ectopic functional thyroid tissue, there can also be fallacies when the normally situated thyroid lobe is not functional and does not take up tracer Tc-99 on radioisotope scanning. Hyper functioning nodule with marked suppression of all other thyroid tissue, neoplasms, inflammations and infiltrative diseases such as amyloidosis can mimic thyroid hemiagenesis. CT angiography can also be undertaken to detect ipsilateral thyroid arteries to further avoid misdiagnosis of non functional thyroid lobe on scintigraphy studies [10].

Over the years CT has been an easily accessible and affordable modality to detect ectopic thyroid tissue effectively and hence has been employed in the absence of a nuclear department. USG of the neck is valuable screening modality for associated thyroid pathologies. Keeping in mind the patient's age, further ionizing radiation studies were not really recommended. Nevertheless, the patient was advised concurrent follow-up as the remnant thyroid tissue is more commonly susceptible to the thyroid pathologies such as functional derangements, morphological changes and autoimmune thyroiditis.

\section{CONCLUSION}

Thyroid hemiagenesis is rare event occurring in the course of thyroid embryogenesis. Usually, it remains undetected clinically until a disease process of the existing lobe brings it under clinical attention. Radionuclide scan and CT angiography are 
investigations of choice for accurate diagnosis which is important to prevent inadvertent thyroid ablation during surgery.

Thyroid hemiagenesis is a rare congenital anomaly, detected as an incidental finding on USG. Computed Tomography/ scintigraphy can help to avoid unnecessary resections prior to surgery. Follow-up with USG and thyroid profile is essential to monitor associated thyroid pathologies.

\section{REFERENCES}

[1] Grant EG, Tessler FN, Hoang JK, Langer JE, Beland MD, Berland $\mathrm{LL}$, et al. Thyroid ultrasound reporting Lexicon: white paper of the ACR Thyroid Imaging, Reporting and Data System (TIRADS) Committee. J Am Coll Radiol. 2015;12(12 Pt A):1272-79.

[2] Prevalence and incidence of rare diseases: Bibilographic data. Available at www.orpha.net/orphacom/cahiers/docs/GB/ Prevalence_of_rare_diseases_by_alphabetical_list.pdf

[3] Elmer R, Kim BK, Lee JW, Jung MJ, Lee EM, Ock SY, et al. A case of thyroid hemiagenesis associated with graves' disease and follicular neoplasm. J Med Cases. 2015;6(8):385-87.

\section{AUTHOR(S):}

1. Dr. Rohini R Pattanshetti

2. Dr. Iranna M Hittalamani

3. Dr. Namit M Garg

4. Dr. Shivu Jayadev

\section{PARTICULARS OF CONTRIBUTORS:}

1. Junior Resident, Department of Radiology, Shri BM Patil Medical College and Research Hospital, Bijapur, Karnataka, India.

2. Junior Resident, Department of Radiology, Shri BM Patil Medical College and Research Hospital, Bijapur, Karnataka, India.

3. Junior Resident, Department of Radiology, Shri BM Patil Medical College and Research Hospital, Bijapur, Karnataka, India.
[4] Sadler TW. Langman's Medical Embryology. $13^{\text {th }}$ ed. Philadelphia, PA: Wolters Kluwer Health; 2015.

[5] Keith L. Moore, T. V. N. Persaud, Mark G. Torchia. The developing human: clinically oriented embryology. $10^{\text {th }}$ ed. Philadelphia, PA: Elsevier Inc: 2016.

[6] Karabay N, Comlekci A, Canda MS, Bayraktar F, Degirmenci B. Thyroid hemiagenesis with multinodular goiter: a case report and review of the literature. Endocr J. 2003;50(4):409-13.

[7] Park SM, Chatterjee VKK. Genetics of congenital hypothyroidism. J Med Genet. 2005;42(5):379-89.

[8] Peña S, Robertson H, Walvekar RR. Thyroid hemiagenesis: report of a case and review of literature. Indian $\mathrm{J}$ Otolaryngol Head Neck Surg. 2011;63(2):198-200.

[9] Shaha AR, Gujarati R. Thyroid hemiagenesis. J Surg Oncol. 1997;65(2):137-40.

[10] Mikosch P, Gallowitsch HJ, Kresnik E, Molnar M, Gomez I, Lind $P$. Thyroid hemiagenesis in an endemic goiter area diagnosed by ultrasonography: report of sixteen patients. Thyroid. 1999;9(11):1075-84.
4. Junior Resident, Department of Radiology, Shri BM Patil Medical College and Research Hospital, Bijapur, Karnataka, India.

\section{NAME, ADDRESS, E-MAIL ID OF THE} CORRESPONDING AUTHOR:

Dr. Rohini R Pattanshetti, Room No B-25, NRI Hostel, Shri BM Patil Medical College, Bijapur-586103, Karnataka, India.

E-mail: drrohinipattanshetti@gmail.com

FINANCIAL OR OTHER COMPETING INTERESTS: None. 